\title{
Modified fine-grained concrete for floor heating system
}

Lidiya Parashchuk $^{\mathrm{a}^{*}}$, Viktoria Kochubei ${ }^{\mathrm{b}}$, Petro Novosad ${ }^{\mathrm{c}}$, Bohdan Seredyuk ${ }^{\mathrm{d}}$, Andriy Hamarnik

a Department of Electromechanics and Electronics, Hetman Petro Sahaidachnyi National Army Academy, Heroiv Maidanu Str., 32, Lviv, 79026, Ukraine

${ }^{\mathrm{b}}$ Department of Physical and Colloid Chemistry, Lviv Polytechnic National University, Bandera Street, 12, Lviv, 79013, Ukraine

${ }^{c}$ Department of Building Production, Lviv Polytechnic National University, Bandera Street, 12, Lviv, 79013, Ukraine

${ }^{\mathrm{d}}$ Department of Electromechanics and Electronics, Hetman Petro Sahaidachnyi National Army Academy, Heroiv Maidanu Str., 32, Lviv, 79026, Ukraine

e Department of Field Artillery, Hetman Petro Sahaidachnyi National Army Academy, Heroiv Maidanu Str., 32, Lviv, 79026, Ukraine

\section{lidadmy@ukr.net}

Keywords: floor heating system, cement screed, fine-grained concrete, modification, dispersive reinforcement, shrinkage.

This work shows the influence of components and hardening conditions on linear shrinkage of finegrain concrete. The floor heating system is one of the most popular options of the heating system these days. The possibility of using this composition for screed for floor heating system is shown. A method of enhancing of strength of the concrete by adding reinforcing fibers and plasticizer has been suggested. Concrete composition has been optimized.

\section{Introduction}

At present stage of the industrial development, with the existing man-made environmental loads, the harmonious development of economy, energy and ecology is highly important. For this purpose it is necessary to take actions for reducing the cost and saving of fuel and energy resources, to introduce new technologies that are based on the alternative and renewable energy sources
(RES), to reduce emissions of harmful substances into the environment.

Modern technologies greatly expand the possible ways of heating of private and suburban buildings. Even though almost all buildings in the 19th century were heated by wood stoves, the backbone heating systems were built in major cities over the past century. However, due to the loss of thermal energy during transportation in centralized networks, which make up $45-60 \%$ and the low level of 
thermal insulation, the consumer receives less of the thermal energy [1].

Recently, renewable energy heating systems have become more and more popular. Such technology as warm floor will help to rise the temperature of the room and thus make it more comfortable. The key advantage of the "floor heating" system, which is often used as ancillary and sometimes as the main source of heat in an apartment or at home, is the most rational use of energy resources [2]. The underfloor heating system saves up to $15-20 \%$ of energy due to the fact that it heats up air in the lower part of the room, while creating a comfortable feeling of warmth at the level of human height. In the case of heating with conventional radiators one have to spend extra power to heat the air throughout the height of the room. The heat from the radiator first rises up to the ceiling and only then falls to the level of human height and below.

\section{Analysis of problem}

The aim of any modern technology including construction is to ensure certain properties of the products being manufactured. Failure to comply with the instructions for use or installation leads to a negation of the benefits of these products and therefore, their irrational use.

The floor heating system is one of the most popular options of the heating system these days. In order to properly perform the installation of the floor heating system, it is important to study the basic information about it and to learn all the intricacies of its laying. The classic layering of the floor heating system is presented in Figure 1 [3].

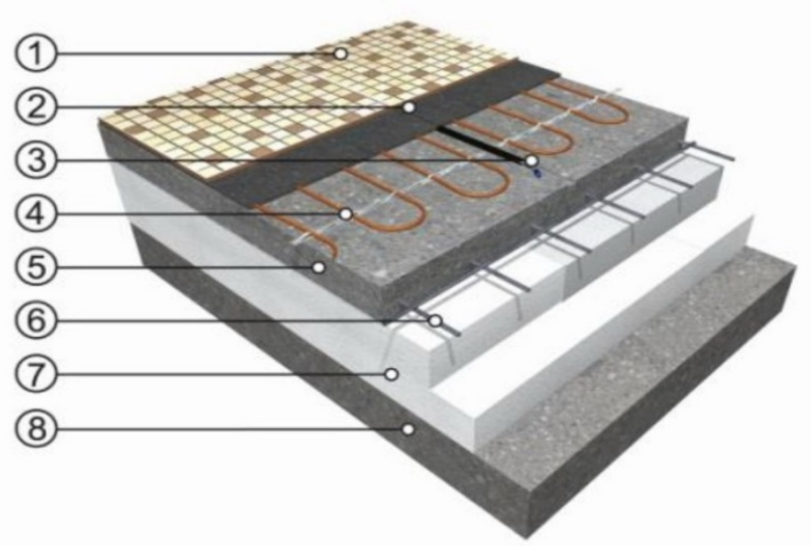

Figure 1. Ordering of layers of the floor heating system: 1 - finishing flooring (laminate, ceramic tiles); 2 - elastic adhesive solution; 3 - thermostat sensor; 4 - cable or floor mat; 5 - cement screed (40-50 mm); 6 - mesh reinforcing; 7 - insulation; 8 - concrete base.

The screed under a floor heating system differs from the usual base, where there are no sharp temperature drops. Due to these differences, it does not crack for a long time, heat is transferred from the floor only to the room and not to the floor slabs. [4]

Four issues can be attributed to the essentials that ensure its durability.

Thermal insulation has to direct the maximum amount of thermal energy indoors and prevent it from spreading down to the floor slabs.

Reinforcement. Owing to the reinforcement of the floor screed with metal it does not collapse under the influence of loads.

The damper tape is designed to withstand the temperature deformation of the 
screed, which causes damage to the heating elements of the warm floor.

Mixture for a floor screed. Properly prepared mortar, which clearly abides to the right proportions of all the necessary components - is the key point of the quality of the floor. The basic requirements for cementsand screed are compression and bending strength to withstand any load, as well as low shrinkage and thermal conductivity [5]. The main characteristic of concrete screed is its density. It depends on the concrete, so 150-300 grade concrete is recommended for warm floors. Concrete of grade 150 is used for residential construction, while grade 300 for industrial. The screed for a warm floor should be filled with fine-grained concrete not with cement-sand mortar, since the former is much stronger than cement-sand mortar, less likely to crack, and provides better heat transfer.

High density of materials is achieved by modifying the structure of the cement matrix with additives of plasticizing action. Due to the water-reducing effect, the amount of water required to achieve easy laying is reduced and the physico-mechanical characteristics of the cementing materials are improved, in particular the porosity and shrinkage are reduced. However, the use of traditional superplasticizers does not lead to the required level of increase in the bending strength of concrete and the increase of fracture toughness.
It is known that the simplest way to increase the tensile strength of concrete (including bending) is its reinforcement with dispersed fibers [6]. The use of steel fibers is impractical for fine-grained concretes. Therefore, it is of interest to use fibers based on basalt, polyethylene, polypropylene, carbon. Strengthening of the material with fibers is based on the fact that the material of the concrete matrix distributes the applied load to the fibers by the tangential forces acting on the surface of the section, and if the deformability of the fiber is less than the deformability of the matrix, then the fibers share the bulk of the applied stress, and the total strength of the composition capacious content [7]. Increasing the tensile strength of cement stone in concretes with arbitrary orientation of the fibers is due to the fact that fibers with sufficient uniformity in the material can withstand forces of almost any direction, and thus prevent the emergence and development of cracks in the cement stone. In the case of force action, defects in the structure can move, merge and subsequently cause cracks to appear and develop. Evenly distributed fibers slow the movement of these microdefects [8]. Under these conditions, studies aimed on increasing of the flexural strength of concretes containing modifying additives and fiber are relevant [9].

Therefore, the research has been mainly focused on the development of fine-grained 
concretecomposition that can be used to arrange screed under the floor heating system.

\section{Experimental part}

\section{Material and methods}

Cements CEM I-42.5 produced by PJSC Podilskyi Cement (Kamianets-Podilskyi, Khmelnytskyi region of Ukraine) obtained from the clinker of the normalized mineralogical composition (mass.\%: $\mathrm{C}_{3} \mathrm{~S}-59,7 ; \mathrm{C}_{2} \mathrm{~S}-18,5$; $\left.\mathrm{C}_{3} \mathrm{~A}-6,6 ; \mathrm{C}_{4} \mathrm{AF}-11,9\right)$ where used in our studies. According to physical and mechanical parameters (Table 1), cement CEM I-42.5 meets the requirements of EN 196-1. Bulk density was $1140 \mathrm{~kg} / \mathrm{m}^{3}$.

Table 1 Physical and mechanical properties of the cement

\begin{tabular}{|c|c|c|c|c|c|c|}
\hline $\begin{array}{c}\text { Specific } \\
\text { surface } \\
\text { A } \\
\mathrm{m}^{2} / \mathrm{\kappa g}\end{array}$ & $\begin{array}{c}\text { Residue } \\
\# 008, \\
\mathrm{wt} \%\end{array}$ & \multicolumn{2}{|c|}{$\begin{array}{c}\text { Setting time, } \\
\text { min }\end{array}$} & \multicolumn{3}{|c|}{$\begin{array}{c}\text { Compressive } \\
\text { strength, MPa, age, } \\
\text { days }\end{array}$} \\
\cline { 3 - 7 } & initial & final & 2 & 7 & 28 \\
\hline 340 & 1.6 & 160 & 250 & 20.5 & 38.5 & 52.4 \\
\hline
\end{tabular}

Natural quartz sand with fineness modulus $\mathrm{M}_{\mathrm{f}}=1.53$ (sand 1), 2.02 (sand 2) i 2.48 (sand 3) with a bulk density of $1420 \mathrm{~kg} / \mathrm{m}^{3}, 1480 \mathrm{~kg} / \mathrm{m}^{3}$ and $1510 \mathrm{~kg} / \mathrm{m}^{3}$ respectively and by voidness of $45.8 \%, 43.5 \%$ and $42.4 \%$ was used as a fine aggregate of fine-grained concrete. The curves of the particle size distribution in the sands are shown in Figure 2. The specific surface of the sands used is 15.3 (sand 1); 12.8 (sand 2) та 8.0 (sand 3) $\mathrm{m}^{2} / \mathrm{kg}$.

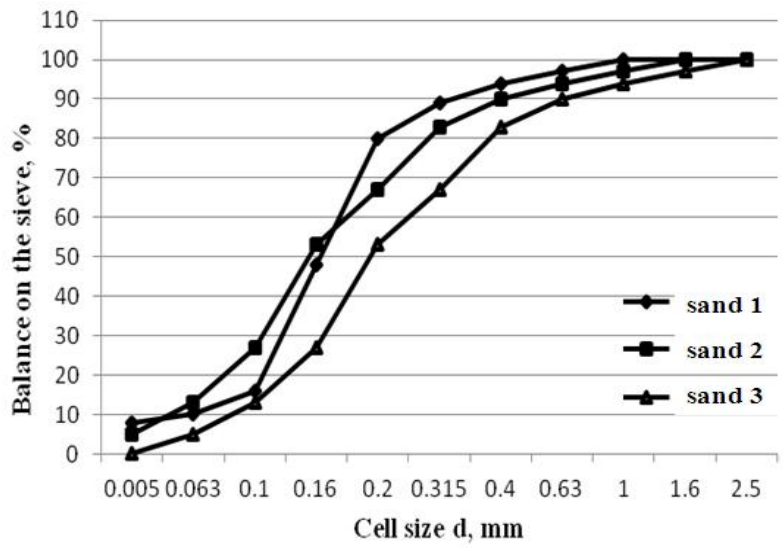

Figure 2. Granulometric composition of sands

Polymethylene naphtalanene sulfonate acid-based plasticizer is used to regulate the rheological characteristics of fine-grained concrete. Bulk density was $630 \mathrm{~kg} / \mathrm{m}^{3}$.

Polypropylene fiber with a length of $6 \mathrm{~mm}$ and a diameter of $18 \mu \mathrm{m}$, which corresponds to TU U 24.7-32781078-001: 2006 was used for dispersive reinforcement. Bulk density was $910 \mathrm{~kg} / \mathrm{m}^{3}$.

The physico-mechanical tests of the samples were carried out according to the European standards, covering the determination of compressive strength and bending strengths of fine-grained concrete by using test beams $(4 \times 4 \times 16 \mathrm{~cm})$. The samples were tested using a hydraulic press $\mathrm{P}-50$. Samples were stored under normal conditions and tested after 1, 7, 14 and 28 days. Linear deformations were determined on test beams of $2 \times 2 \times 8 \mathrm{~cm}$ size using the IZV-3 optical micrometer. Special covers with holes were stuck on the sample to determine the variations in length along an axis 
that is selected. The measurements were carried out within 28 days of hardening under normal conditions with an accuracy of $\pm 0.001 \mathrm{~mm}$. One part of the samples hardened under normal conditions, the other under conditions where there is practically no evaporation of water. These samples were covered film by polyvinyl acetate-based. This film was waterproof.

\section{Results and discussion}

It is known that the aggregate content, its granulometric composition and specific surface area are of great importance during the formation of concrete structure [10]. To investigate the influence of fraction composition of quartz sand on physico-mechanical characteristics the composition of fine concrete that serves as a screed under floor heating system the sample beams of $2 \times 2 \times 8 \mathrm{~cm}$ size from mortar of a cement:sand ratio $1: 1$ at $\mathrm{w} / \mathrm{c}=0.3$ were formed. The results are shown in table 2.

Table 2. Influence of fractions composition of quartz sand on physic-mechanical properties of fine-

grained concrete

\begin{tabular}{|c|c|c|c|}
\hline \multirow{2}{*}{$\begin{array}{c}\text { Age, } \\
\text { days }\end{array}$} & \multicolumn{3}{|c|}{$\begin{array}{c}\text { Bending /compressive strength, MPa, } \\
\text { with sand fractious }\end{array}$} \\
\cline { 2 - 4 } & Sand 1 & Sand 2 & Sand 3 \\
\hline 1 & $2.6 / 11.2$ & $3.6 / 11.8$ & $3.0 / 9.7$ \\
\hline 7 & $8.1 / 33.4$ & $8,7 / 42.6$ & $9.0 / 37.2$ \\
\hline 14 & $8.7 / 44.5$ & $10.1 / 43.8$ & $9.9 / 41.5$ \\
\hline 28 & $9.2 / 45.7$ & $10.7 / 50.5$ & $10.1 / 44.5$ \\
\hline
\end{tabular}

The maximum at all curing ages is shown by the samples, using sand 2 with a modulus of 2.02. The use of sand containing fine and coarse fractions increases the physical and mechanical characteristics of concrete. This effect is explained by the fact that the small fraction can act as a fine aggregate and microfiller at the same time.

Ordinary Portland cement-based concrete shrinks as it dries out. This causes tensile stress that often exceeds the strength of concrete, resulting in cracks formation in the initial age [11]. A significant difference in the degree of shrinkage is observed when the samples harden in conditions where there is practically no evaporation of water (Figure 3).

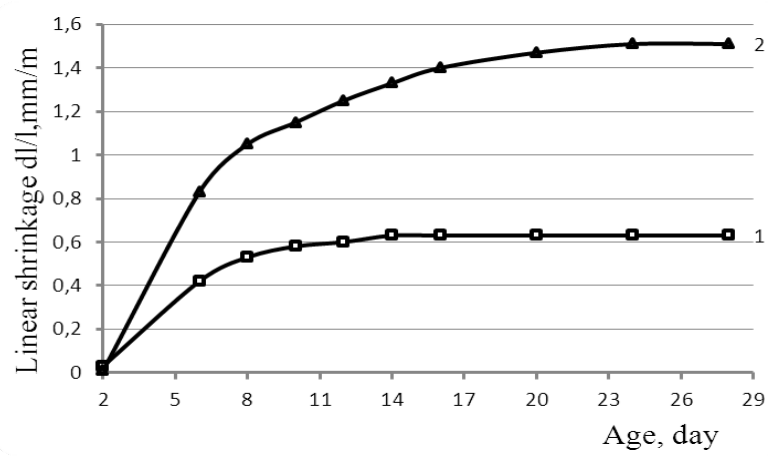

Figure 3. Shrinkage of the cement paste: 1 - with coating; 2 - without coating.

In this case, the shrinkage degree decreases by 2.1 and 2.5 times respectively after 7 and 28 days. It should be noted that shrinkage stabilization in the case of coated specimens occurs after 10 days. Shrinkage of uncoated samples was stabilized after 21 days.

The results of studies of the effect of sand fineness of fine-grained concrete which was hardened under conditions where there was essentially no water evaporation on the degree of shrinkage are presented in Figure 4. 


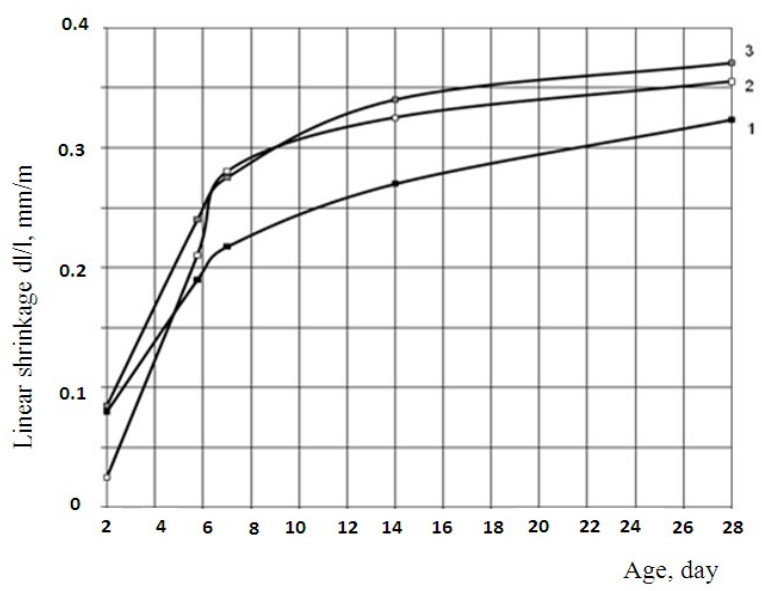

Figure 4 Kinetics of linear shrinkage degree variations of fine-grained concrete with the sand of various fineness: $\mathrm{Mf}=1.55(1) ; \mathrm{Mf}=2.02(2) ; \mathrm{Mf}=2.48(3)$

The degree of shrinkage for the sample with sand 3 was found to be the highest $0.38 \mathrm{~mm} / \mathrm{m}$. With a decreasing fineness modulus the value of stone shrinkage decreases to 0.35 and $0.32 \mathrm{~mm} / \mathrm{m}$ for the samples with sand 2 and 1 respectively. As it follows from the above, to reduce shrinkage of the samples it is necessary to use sand with a smaller fineness modulus.

To investigate the influence of fine aggregate amount (silica sand №2) on physicomechanical characteristics the composition of fine concrete was optimised. The samples of $4 \times 4 \times 16 \mathrm{~cm}$ size containing silica sand of 25 $75 \mathrm{wt} \%$ were prepared at $\mathrm{w} / \mathrm{c}$ ratio of 0.28 . The results are shown in table 3.

As it can be seen from the table, the increase in the mass fraction of sand reduces concrete's strength characteristics. The most intensive increase in strength is observed between 1 and 7 days for all the samples of all the compositions. As the sample with $30 \mathrm{wt} \%$ content of sand has the highest value of bending strength (15.2 MPa vs. 14.4 MPa for the sample with $25 \mathrm{wt} \%$ of sand and $11.4 \mathrm{MPa}$ for the sample with $40 \mathrm{wt} \%$ of sand). To that, no reduction is to be observed in strength. From an economic consideration, the optimal ratio of cement-to fine aggregate is $1: 3$.

Table 3. The influence of fine aggregate on physical and mechanical properties of fine-grained concrete

\begin{tabular}{|c|c|c|c|}
\hline \multirow{2}{*}{$\begin{array}{c}\text { Age, } \\
\text { days }\end{array}$} & \multicolumn{3}{|c|}{$\begin{array}{r}\text { Bending/compressive strength, MPa, } \\
\text { at content of sand, \% }\end{array}$} \\
\cline { 2 - 4 } & 25 & 30 & 40 \\
\hline 1 & $6.3 / 16.5$ & $6.2 / 16.4$ & $4.2 / 15.5$ \\
\hline 7 & $13.2 / 55.7$ & $9.6 / 47.5$ & $9.2 / 45.9$ \\
\hline 14 & $13.6 / 60.4$ & $14.2 / 58.3$ & $11.2 / 47.8$ \\
\hline 28 & $14.4 / 63.6$ & $15.2 / 60.8$ & $11.4 / 54.8$ \\
\hline & 50 & $67(1: 2)$ & $75(1: 3)$ \\
\hline 1 & $3.6 / 11.8$ & $3.2 / 10.6$ & $3.0 / 9.7$ \\
\hline 7 & $8.7 / 42.6$ & $8.1 / 43.1$ & $7.3 / 32.4$ \\
\hline 14 & $10.1 / 43.8$ & $9.4 / 44.8$ & $8.3 / 38.6$ \\
\hline 28 & $10.7 / 50.5$ & $10.5 / 47.2$ & $10.1 / 40.8$ \\
\hline
\end{tabular}

The next stage of the research concerns the effect of dispersed reinforcement of an optimal composition of finely grained concrete by basalt fiber on its performance. Manufacturer recommends fiber proportioning in the amount of $0.9 \mathrm{~kg} / \mathrm{m}^{3}$. However, in this study a fine-grain concrete of specific composition has been suggested, therefore it makes sense to establish the optimal amount of fiber. To examine the effect of a fiber amount on physical and mechanical properties of concrete, the test beams were prepared by adding of $0.25 ; 0.5$; 0.75 and $1.0 \%$ fibers of cement weight. The results are presented in table 4. 
Table 4. Influence of amount of fibre is on physicmechanical properties of fine-grained concrete

\begin{tabular}{|c|c|c|c|c|c|}
\hline \multirow{2}{*}{$\begin{array}{l}\text { Age, } \\
\text { days }\end{array}$} & \multicolumn{6}{|c|}{ Bending/compressive strength (MPa) depending on } \\
a fiber amount, wt \% \\
\cline { 2 - 6 } & 0 & 0.25 & 0.5 & 0.75 & 1.0 \\
\hline 1 & $4.0 / 9.7$ & $5.1 / 20.8$ & $7.3 / 24.1$ & $7.6 / 24.6$ & $8.1 / 24.8$ \\
\hline 7 & $6.2 / 32.4$ & $11.3 / 36.1$ & $11.8 / 38.6$ & $12.4 / 39.4$ & $12.7 / 39.9$ \\
\hline 14 & $8.7 / 39.6$ & $12.1 / 46.4$ & $13.7 / 50.1$ & $14.6 / 51.4$ & $14.8 / 51.4$ \\
\hline 28 & $10.1 / 42.8$ & $13.4 / 51.9$ & $14.3 / 52.9$ & $15.1 / 53.8$ & $15.1 / 54.1$ \\
\hline
\end{tabular}

The table shows that adding of $0.25 \%$ of fiber significantly improves strength characteristics of concrete. The major increment occurs in the period of up to 14 days. After that it is not as significant. To that, the dispersed reinforcement more increasingly affects the bending strength. Further increase in the fiber amount is found to be economically inefficient.

Since the modification of the concrete is quite complex [12-14], the strength characteristics of the specimens during bending and compression were determined with each additive separately and their combination in optimal quantities (Figure 5).

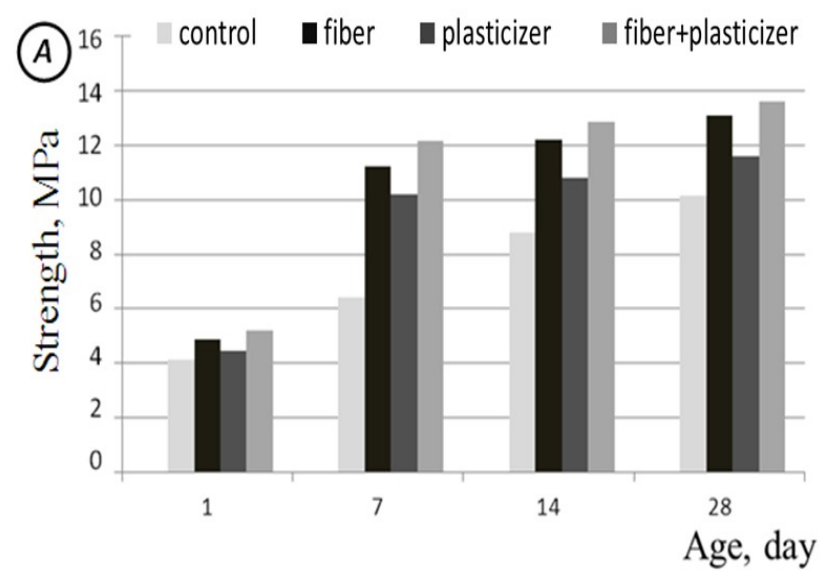

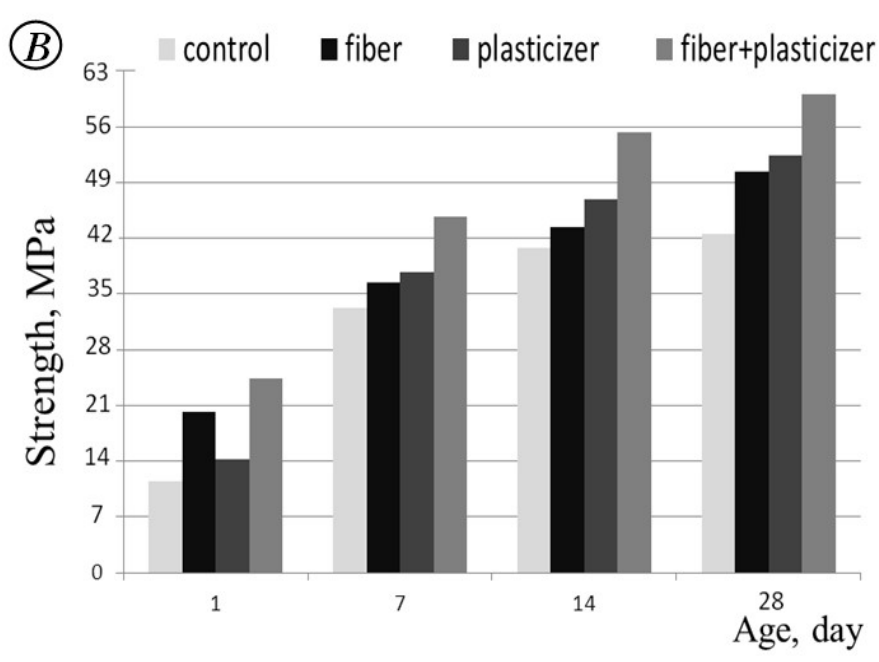

Figure 5. Influence of optimal content of different additions on physical and mechanical properties of finegrained concrete: A - bending strength, B - compressive strength.

The figure clearly demonstrates that the introduction of fine-grained plasticizer into concrete mainly affects the compressive strength, improving it after 28 days by almost $10 \%$ compared to the sample without additives. However, the improvement of flexural strength is also achieved by the introduction of fiber. The simultaneous introduction of these additives provides a synergetic effect and that results in overall improvement of strength characteristics up to $25 \%$.

For these modified compounds, the magnitude of the linear shrinkage was measured under conditions where there was practically no evaporation of water and a corresponding graph of dependence is presented in Figure 6. 


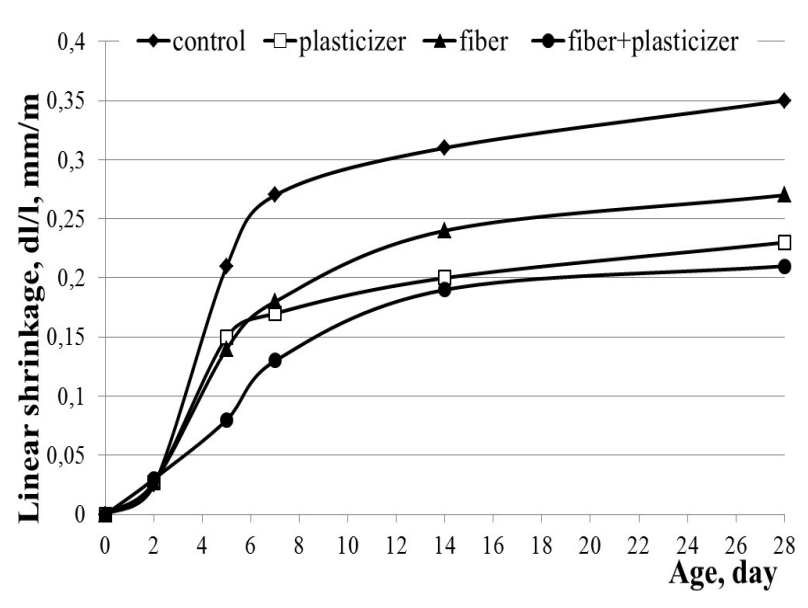

Figure 6. Kinetic of linear shrinkage degree

variations of fine-grained concrete with different modified additives

As it can be seen from the figure 5, the fiber and plasticizer reduce linear shrinkage from $0.35 \mathrm{~mm} / \mathrm{m}$ to 0.26 and $0.23 \mathrm{~mm} / \mathrm{m}$ respectively. However, the most effective is the simultaneous introduction of fiber and plasticizer into the screed. This technique makes it possible to reduce linear shrinkage to $0.21 \mathrm{~mm} / \mathrm{m}$.

For customer or production, it is comfortable to show the optimal composition of fine-grained concrete in a more usual form: material consumption per $\mathrm{m}^{3}$ of the prepared concrete mortar. Considering the true and bulk densities of raw materials and some other parameters required for the calculation obtained the ratio between the components:

$$
\begin{aligned}
& \text { Cement }-489 \mathrm{~kg} \\
& \text { Sand }-1467 \mathrm{~kg} \\
& \text { Water }-1371 \\
& \text { Fiber }-1.22 \mathrm{~kg} \\
& \text { Plasticizer }-2.45 \mathrm{~kg}
\end{aligned}
$$

\section{Conclusions}

Our studies reveal that modified finegrained concrete, but not a cement-sand mortar should be used to ensure the functional and operational characteristics of warm floors. The sand used and its amount play an important role in its preparation. It is experimentally established that the optimal ratio of cement: small filler is $1: 3$. In this case, it is better to use sand with a lower modulus, since it exhibits smaller values of shrinkage deformations and the ability to crack respectively. The effect of modifying additives and their optimal amount on the strength and deformation properties of fine-grained concrete is established. The introduction into the concrete composition of the optimal amount of reinforcing fiber and plasticizer, as well as coating it with a film that prevents evaporation of water allows to reduce the deformation properties of the shrinkage up to $0.21 \mathrm{~mm} / \mathrm{m}$ and increase the strength characteristics by $25 \%$, compared with the composition without additives. The use of such techniques will give the screed under a warm floor such properties, thanks to which it will be characterized by high quality and long service life.

\section{References}

[1] Sotnik M. I. et al. Simulation of the thermal state of the premises with the heating system «Heat-insulated floor». East Eur J Enterp Technol. 2015; 5 (78): 22-27.

[2] Horka Lucie, Hirs Jiri Transient simulation study of floor heating systems. IJASE 2019; 10 (1): $35-41$. 
[3] Shin M. S., Rhee K. N., Ryu S. R., Yeo

M. S., Kim K. W. Design of radiant floor heating panel in view of floor surface temperatures. BUILD ENVIRON 2015; 92: 559-577.

[4] Basok B., Tkachenko M., Nedbailo A., Bozhko I. Research into energy efficiency of the underfloor heating system, assembled dry. Industrial And Technology Systems:Technology And System Of Power Supply 2018; 3/1(41):52-57.

[5] Esmaeel Khanmirza, Ahmad Esmaeilzadeh, Amir Hossein, Davaie Markazi. Design and experimental evaluation of model predictive control vs. intelligent methods for domestic heating systems. ENERG BUILDINGS. 2017, 150: 52-70.

[6] U. Marushchak, N. Sydor, S. Braichenko, I. Margal, R. Soltysik. Modified fiber reinforced concrete for industrial floors. Paper presented at: IOP Conference Series. Materials Science and Engineering. 2019, 708(1): 012094.

[7] L. Parashchuk, V. Kochubei, Ya. Yakymechko The use of granulated lime for expansive cement with high-energy self-tension. Chem.Chem.Technol. 2011, 5(3): 341-345.

[8] Tomas U., Ganiron Jr. Influence of Polymer Fiber on Strength of Concrete. IJAST 2013, 55: 53-66.

[9] M. Stechyshyn, M. Sanytskyy, O. Poznyak Durability properties of high volume fly ash selfcompacting fiber-reinforced concretes. East Eur J Enterp Technol. 2015, 3/11(75): 49-53.

[10] Han V., Ros S., Shima H. Effects of Sand Content, Superplasticizer Dosage, and Mixing Time on Compressive Strength of Mortar. ACI MATER J. 2013, 110: 23-31.

[11] A.B.Eberhardt, R.J.Flatt Working mechanisms of shrinkage-reducing admixtures. In book: Science and Technology of Concrete Admixtures, Chapter: 13, Publisher: Woodhead Publishing, Editors: P.-C. Aitcin, R.J. Flatt; 2016. p.305-320.
[12] Krivenko P, Runova R, Rudenko I, Skorik V, Omelchuk V Analysis of plasticizer effectiveness during alkaline cement structure formation. East Eur J Enterp Technol. 2017, 4/6(88):35-41.

[13] Tolmachov S., Belichenko O., Zakharov D. Influence of additives on flexural strength of concrete. Paper presented at: MATEC Web of Conferences, Transbud 2017, 116; 01019.

[14] Plank J, Schroefl C, Gruber M, Lesti N, Sieber $\mathrm{R}$ Effectiveness of polycarboxylate superplasticizers in ultra-high strength concrete: the importance of PEC compatibility with silica flume. J Adv Concr Technol 2009, 7(1):5-12.

(1)

